\title{
THE USE OF ULTRA HIGH PERFORMANCE FIBRE REINFORCED CEMENT-BASED COMPOSITES IN REHABILITATION PROJECTS: A REVIEW
}

\author{
MARTÍN-SANZ, H. , CHATZI, E. ${ }^{\dagger}$ AND BRÜHWILER, E ${ }^{\dagger \dagger}$ \\ *ETH Zürich \\ Zurich, Switzerland \\ e-mail: martin-sanz@ibk.baug.ethz.ch \\ ${ }^{\dagger}$ ETH Zürich \\ Zurich, Switzerland \\ e-mail: chatzi@ibk.baug.ethz.ch \\ ${ }^{\dagger \dagger}$ EPFL Lausanne \\ Lausanne, Switzerland \\ e-mail: eugen.bruehwiler@epfl.ch
}

Key words: UHPFRC, Retrofitting, Numerical Simulation, Structural Health Monitoring.

\begin{abstract}
Ultra High Performance Fibre Reinforced cement-based Composites (UHPFRC) form a novel material developed over the last two decades. A set of special traits, such as durability, outstanding material properties, and ease of application, render UHPFRC particularly attractive for the improvement (rehabilitation, strengthening) of concrete structures. Laboratory tests indicate a compressive strength, which ranges from 150 to $200 \mathrm{MPa}$, while tensile strength lies in the range of 7-15 MPa. The fibres play an important role in defining the range of these properties depending on the content (3-6\%), orientation, length and composition. As a consequence, UHPFRC delivers a workable material whose mechanical properties may be properly adjusted according to the desired application scheme. As indicated via laboratory testing and in-situ experience, the durability of the structure may be extended not only due to the properties of UHPFRC but also due to the additional protection it offers to the reinforcement. This paper provides an overview on existing findings of UHPFRC implementations, focusing in the domain of improvement of structures. Within this context, UHPFRC may be applied on top of existing bridge decks [1],with or without steel rebars, ensuring full bond conditions via mere surface preparation prior to casting. In exploiting the attributes of UHPFRC within a rehabilitation context, further applications are being explored, such as strengthening of orthotropic steel decks in order to prevent fatigue issues [2]. Nonetheless, it should also be acknowledged that certain aspects need to be improved such as the development of a multi scale analysis framework, able to provide a detailed computational method without detriment to time efficiency. The introduction of monitoring technologies in structures with UHPFRC would unquestionably provide valuable insight into its long-term performance and help validate this scheme for the next generation of rehabilitation interventions.
\end{abstract}

\section{INTRODUCTION}

Ultra High Performance Fibre Reinforced cement-based Composites (UHPFRC) is a material that has evolved over the last two 
decades, overcoming the brittleness of Ultra High Performance Concrete (UHPC) via addition of fibres into the cementitious matrix, thus leading to exceptional mechanical and durability properties [3]. The characteristic properties used to identify this material include strain softening and strain hardening in tension, ductility, toughness and fracture energy. Diverse target properties can be tailor-designed by modifying several specific parameters, such as type of fibres and its volume fraction, direction of casting and matrix composition. Therefore, values in tension strength vary from 8 to $15.9 \mathrm{MPa}$, while in compression the range goes from 150 to in excess of $200 \mathrm{MPa}$. Another remarkable key strength of the UHPFRC involves its performance under severe environmental conditions such as humidity, chloride ions, thermal loads or life cycle considerations [4], due to the low porosity of the material and the microcrack control it exhibits. Hence, UHPFRC reveals itself as particularly suitable for rehabilitating structural elements by waterproofing them, thereby prolonging lifespan and enhancing durability.

In this context, significant work has been conducted on fatigue tests, not only with the material alone but also UHPFRC containing rebars or in combination with concrete beams [5].

In recent years, related research has been extended to its behaviour in compound systems, as Reinforced UHPFRC (R-UHPFRC), layers of UHPFRC on top of concrete beams or slabs (R-UHPFRC-RC) or steel decks. Consequently, the bond between surfaces has been studied [6], leading to the finding of a perfect monolithic behaviour between UHPFRC and concrete or steel rebars. Moreover, the performance of the conventional systems is clearly enhanced by addition of the UHPFRC, in terms of flexural, tension and shear strength, along with the aforementioned fatigue and durability benefits.

UHPFRC has been applied in a multiplicity of projects, albeit bridges comprise the category, which has majorly benefited the most from this solution. In some cases, elements suffering from severe or prolonged exposure to aggressive environments need to be protected, as piers in contact with de-icing salts, curbs, crash barriers or retaining walls. Additionally deck slabs are subjected to increased live loads and fatigue, thus UHPFRC can restore lost strength and further increase load carrying capacity to a required level while adding a waterproof layer [7].

In addition to bridges, further structures have been rehabilitated with UHPFRC, such as concrete building slabs and maritime lighthouses. Recently, fatigue issues in orthotropic steel decks have been overcome by adding a layer of precast slabs connected to the plate by means of miniature Nelson studs [8] Ease of application is one of the main advantages provided by this material. For example, application of a 30 to $40 \mathrm{~mm}$ layer of UHPFRC over a concrete surface, which has been prepared by high pressure water jetting, is accomplished using a conventional ready mix plant, conventional truck transportation and tools for the pouring [9]. Compressive strength can reach $80 \mathrm{MPa}$ and $100 \mathrm{MPa}$ after one and two days, respectively, allowing high speed of construction, reduction in costs and diminution of traffic cuts or non-operational times.

Although UHPFRC has been proven to work efficiently with other materials, the complexity of the composite system needs to be considered when modelling its behaviour. Two different approaches for simulation have been developed in order to reduce computational time and to obtain results accurate enough for the purposes of structural analysis. The first one models the material as isotropic and defines the strain hardening and softening domains by means of changes in the modulus of elasticity [10]. The second one uses a Multiscale Hierarchical Simulation, either assuming bridging stress of fibres and its relationship with crack opening displacement [11] or bond stress-slip behaviour of fibres at the meso-level [12]. FEM models study UHPFRC, R-UHPFRC and also RUHPFRC-RC; however, limited amount of literature has been found regarding multiscale simulation and compound designs, restricting the calculations to UHPFRC alone.

Further development of numerical approaches is necessary, not only to correctly design the material and exploit its properties where the 
effects can be more useful, but also to help tracking the behaviour of the systems along their future service lives. Monitoring of existing structures provides essential information for the evaluation of safety conditions, thus rehabilitated components should specially be considered when realizing a monitoring campaign. In this context, numerical models play an important role in structural identification failures, by using modal data information (natural frequencies and mode shapes) [13].

Given this background, the work presented herein is organized as follows. First, the material properties are described in detail, with special focus in the characteristics that highlight UHPFRC material as a valuable technology for improving structures. Second, a summary of the available literature regarding numerical simulation is presented, including both FEM and Multiscale approaches. Next, several examples of improvement projects with UHPFRC are shown, including a comparison with convectional techniques in terms of cost, effectiveness and easiness of application. The fourth chapter addresses monitoring schemes that have been developed for the follow up of UHPFRC behaviour in combination with existing structures. Finally, aspects to be improved are acknowledged, in particular the behaviour of the material under long-term effects and the correction of arising issues.

\section{GENERAL PROPERTIES}

Research in UHPFRC is constantly evolving leading to improved properties and enhanced behavior. In order to obtain a dense matrix with very low permeability, the maximum grain size has to be controlled, as well as the cement volume content, water/binder ratio and the type of superplasticizer employed. Over the past few years, focus has been shed in reducing the $\mathrm{CO}_{2}$ footprint of the material, primarily by lowering the amount of cement via use of limestone filler [14], while increasing the maximum tensile strength [15].

In improving material properties, it is critical to attain a better understanding of the matrix constitution and the bond between fibres. The bridging effect of the fibres, in particular, significantly affects performance in the hardening and softening domain. According to Naaman and Reinhardt [16], strain hardening occurs as result of the tensile strength, $\sigma_{\mathrm{pc}}$, exceeding the cracking stress, $\sigma_{\text {cc }}$. The tensile behavior of UHPFRC is categorized into three different phases (Figure 1) [17]: Zone I, or the strain based elastic part, up to $\sigma_{\mathrm{cc}}$, the stress level defined by $\varepsilon_{\mathrm{cc}}$ and $\mathrm{E}_{\mathrm{cc}}$ where the material enters its strain hardening behavior; Zone II, or the strain based hardening domain, determined by the dissipated energy per unit volume $g_{f, A}$, the $99 \%$ tensile strength of the composite $\sigma_{p c}$, its associated strain $\varepsilon_{p c}$, and where cracking begins, the hardening modulus $E_{h c}$, and the residual strain $\varepsilon_{\text {res; }}$; and Zone III or the crack opening based softening part, defined by the dissipated energy per crack surface area $G_{f, B}$.

The orientation, volume content and type of fibres determine the properties of UHPFRC and induce a certain variability. For example, plastic fibers such as polypropylene increase the compressive strength by $2.5 \%$ in comparison to the mix without fibers, whereas steel achieves an increase of 6\% [18]. Further research is being conducted on this topic, aiming for a more sustainable material with less steel fiber content. Along with its mechanical properties, the high density and lower porosity of UHPFRC enable outstanding results in terms of durability, when compared to ordinary concrete or even to High Performance Concrete (HPC). For instance, the freeze-thaw problem is negligible for UHPFRC. 


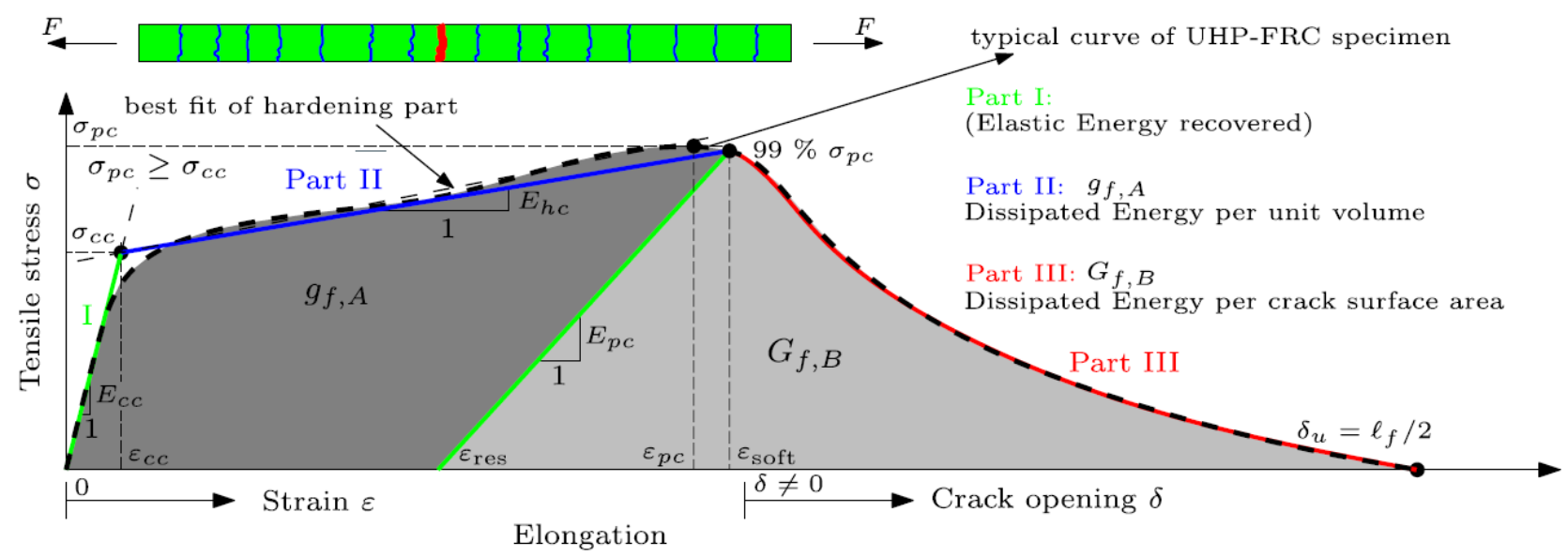

Figure 1 Strain hardening tensile behavior of UHPFRC and idealized modeling approach (horizontal axis magnified) (Figure reused from [17])

Moreover, no carbonation, chloride ion ingress or sulphate reaction occur as the material is waterproof. At this point, it need be noted, that not only the steel rebar benefits from the particular relationship between both elements in UHPFRC; the material's tensile behaviour is enhanced by the steel rebar, with the added benefit of minimizing the scatter in the general properties.

In consideration of these results, research has been conducted on R-UHPFRC attached to concrete elements, with a particular focus in the bond between both materials and the performance under fatigue loading. Regarding the former, several tests indicate perfect monolithic behaviour for R-UHPFRC-RC, obtained by means of concrete surface preparation (high pressure water jet or sand blasting), exhibiting no debonding between layers [6],[19]. Although it is recommended that new materials feature similar characteristics when combined with original concrete elements in order to achieve composite performance, a number of reasons support the functionality of the mechanism composed by a layer of UHPFRC on top of concrete.. Firstly, in the elastic domain, the difference in the $\mathrm{E}$ modulus (55 GPa for UHPFRC versus $35 \mathrm{GPa}$ for normal concrete) is compensated by the aforementioned improved tensile strength. Secondly, strain hardening in UHPFRC is significantly larger than its maximum elastic elongation, contrary to conventional concrete. Eventually, autogenous shrinkage is the predominant part of internal UHPFRC deformation and drying shrinkage could be neglected after 8 days of moist curing [20]. With respect to fatigue, the response of UHPFRC varies depending on the configuration. The material alone under tensile fatigue stresses endures ratios of maximum fatigue stress to elastic limit strength ranging from 0.45 to 0.70 , whereas R-UHPFRC and RUHPFRC-RC failure is determined by the fracture of steel rebars in the R-UHPFRC layer. Bending fatigue tests in R-UHPFRC-RC beams up to 10 million cycles have established a fatigue limit at a solicitation $50 \%$ of the ultimate static strength.

\section{MODELLING OF UHPFRC}

Particular attention is required when simulating composite material performance in the strain hardening domain. The bridging effect of the fibers, the transmission stresses manifested at occurrence of the first crack, along with the propagation of cracks in the softening domain, demand an adapted formulation of existing calculation procedures.

Three main approaches have been developed towards efficient simulation. Their formulation, as well as their validation by means of laboratory testing, are summarized herein. 


\section{Modelling stress- strain behavior}

The simulation schemes, which model the cracked element as a continuum and subsequently adapt the stress-strain behavior, are the most commonly met in existing literature. This review focuses on the latest achieved developments, for UHPFRC, UHPFRC-RC and R-UHPFRC-RC.

Simulation of the material alone has been successfully carried out by Tysmans et al. [10] by means of a modified version of Concrete Damaged Plasticity (CDP), validating the results with an in-plane biaxial loading test setup. In [21], a computational damage model is developed, considering a global and local softening behavior formulation. In [22] UHPFRC is modeled across two scales, the section and tensile element scale. In the case of R-UHPFRC a tension chord modeling approach is frequently adopted, as followed in the works of Xia, J. [11] and Sadouki, H., Denarié, E., Žnidarič, A. et al [23]. Modeling of RUHPFRC-RC is of particular significance within the context of rehabilitation and strengthening of structural elements, as indicated in [24], where UHPFRC was used in a concrete deck improvement project.

\section{Multiscale simulation with fiber interaction and matrix in the same element}

Multiscale approaches, in the UHPFRC context, operate in two distinct scales, i) the fine scale, which considers the multiple fibers and simulates the fracture of the matrix and the pullout behavior, and ii) the coarse scale deals, which with structural response at a macroscopic level. Within this context Ellis et al. [25] employ Rigid-Body-Spring-models, assuming that after cracking of the matrix the entire stress is carried by the fibers. A blast-loading test was employed for validating this methodology.

Despite the multiscale approach comprising a more recent development in UHPFRC simulation, some efforts are already extended to the modeling of R-UHPFRC, as in the work of Trüb [26], who combines a Smeared Crack and Discrete Crack model.

\section{Multiscale simulation with fiber interaction and matrix as different elements}

In models based in bond stress-slip behavior of the fibers at the meso-scale level, matrix and fibers are characterized separately. Consequently, the location of each fiber need be known. In [27], this definition is achieved by mean of parametric analyses relying on probability distributions of matrix strength and fiber distribution.

\section{IMPLEMENTATION OF UHPFRC IN REHABILITATION AND STRENGTHENING PROJECTS}

As mentioned before, UHPFRC exhibits properties, which render it particularly suitable for rehabilitation and strengthening of concrete structural elements. The advances achieved over the last few years, in terms of enhancement and knowledge refinement, have led to a widespread use in various domains. Several examples are listed below, categorized according to the type of improved element.

\section{Improved concrete beams}

Three different configurations were analyzed in [28]. UHPFRC layers were added a) in the tensile zone, b) the compression zone, and c) as a three-side UHPFRC jacket. All cases indicate a tensile strength improvement of the overall system, with the latter approach being the most effective. Wang et al [29] used UHPFRC panels to improve shear resistance and ameliorate the failure of beams, demonstrating positive effects.

\section{Improved concrete bridges}

Deck slabs of bridges are particularly well suited for rehabilitation and strengthening using UHPFRC. The general procedure comprises in firstly eliminating the top 20-40 mm of RC, by means of high pressure water or sand blasting, and subsequently pouring a layer of RUHPFRC, of a width ranging from 20 to $70 \mathrm{~mm}$ depending on the project. This layer can also be used as a waterproof membrane. Bastien-Masse and Brühwiler [1],[30] have studied the response under punching effects in the 
connection zone between deck and piers. The Log Čezsoški bridge rehabilitation in Slovenia is overviewed in [31] along with comparative evaluation of the influence of global warming on different materials, such as standard concrete, ECO concrete, standard UHPFRC or ECO UHPFRC, revealing the benefits of the last mentioned when examined within the scope of the structure's life-cycle. In [32], a comparison is made in monetary terms with regards to the work performed on a bridge over Morge river in Switzerland, involving not only the deck but additionally UHPFRC kerbs. Following the same line, Brühwiler and Denarié [7] compile a comprehensive reporting of rehabilitation projects carried out in Switzerland from 2004 till 2015. The latest application in Switzerland pertains to a viaduct suffering an Alkali-Silica Reaction (ASR) problem among other issues [33]. The applied layer of UHPFRC serves two missions: a) to control the ASR expansion by virtue of the low porosity of the material and $b$ ) to enhance the strength of the deck slab by $40 \%$. Another innovative procedure for I girder bridges is developed in France [34], where two continuous side cheeks were cast in situ on the bottom heels on either side of the beam webs, allowing work to be performed more cheaply and faster than by conventional methods. In North America, even if the tendency is to use UHPFRC for new structures, examples of interventions on existing bridges are limited to UHPFRC precast slabs to replace concrete decks [35] as well as to the filling of dilation joints.

\section{Improved orthotropic steel decks}

Increasing traffic and loads, along with the fatigue and corrosion steel suffers, constitutes a problem for steel bridges entailing expensive repair measures, although UHPFRC is becoming a new instrument to solve this issue. Sato et al [36] have tested the mechanical behavior of the interface, either epoxy resin or shear studs, showing better performance with the first method and an ultimate resistance characterized by debonding failure. Similar results are obtained in [37]. Moreover, an application on a real bridge was carried out in France [39] by means of precast UHPFRC slabs, attached to the steel deck through steel studs. With this procedure, the service life of the structure is expected to increase by at least 20 years, due to the stiffness increase and consequently a reduction of fatigue stresses.

\section{Improved railway steel bridges}

The Buna Bridge in Croatia [41], was built in 1893, comprises two main girders made of riveted hot rolled steel plates, stiffened with vertical and horizontal girds. With the opportunity of its complete replacement, the original structure was transported and tested within a laboratory setting, prior to and after the implementation of a cast in-situ UHPFRC deck. In early reporting, the center of gravity of the new composite section appears to have risen, allowing the introduction of additional loads and eliminating the stability concerns in the compression zones.

\section{UHPFRC in hydraulic environments}

Guingot et al [41] present several rehabilitation works performed in France, where structures such as dams, bridge channels or hydroelectric plants needed to be protected from water impact, abrasion and extreme environmental conditions. Furthermore, Denairé et al. [42] have introduced an innovative method to rejuvenate a turret, by casting UHPFRC from a helicopter and pouring over a special formwork surrounding a masonry structure.

\section{Other applications}

Extensive research has been conducted on Carbon Fiber Reinforced Polymer (CFRP) and Glass Fiber Reinforced Polymer (GFRP) as repair materials for fire-damaged concrete. UHPFRC has been tested by Hizami Abdullah et al [43], within the context of fire safety, and its performance was compared to conventional materials, revealing significant improvement in stiffness and bond strength. In a related experimental study, the performance of UHPFRC jackets under seismic action is investigated [44], demonstrating that failures 
such as lap splice fracture, concrete cover spalling and longitudinal bar buckling in columns may be effectively eliminated. According to Tsonos [45], structures rehabilitated with Fiber reinforced Polymers (FRPs) present a weak point in the area of beam-column joints during seismic events, thus an additional local UHPFRC jacket has been proposed, resolving the aforementioned issue.

\section{MONITORING OF UHPFRC STRUCTURES}

Structural Health Monitoring (SHM) is a powerful tool that has gained considerable acceptance in recent years in both the research and practice. Rehabilitated and strengthened UHPFRC structures pose an excellent case for implementation of this technique, as important information regarding short- and long-term performance of this new material, as well as data on the global response of the improved system, can be extracted.

Structural Health Monitoring utilizes sensor deployments for the traction of significant information from the system, and this may be carried out either via periodic campaigns, commonly Non Destructive Evaluation (NDE) methods, or long-term campaigns featuring a permanently installed sensor grid [38]. Ideally, monitoring should be performed prior to and after the intervention on the system, in order to obtain a better understanding of the failure mechanisms, their exact locations and how to effectuate the improvement. A comparison between both the damaged and improved state helps asses the effectivity of the intervention and to estimate the duration of the new service life of the improved structure.

An SHM approach is implemented in the work of Hajar et al. [39], already discussed in the chapter of orthotropic steel decks, where a monitoring campaign was carried out both in the months preceding the intervention and after its completion, in order to determine the impact on fatigue accumulation. The scheme was configured via the use of 72 strain gauges, attached to the bridge soffit and the main girders. Although only general trends were extracted, the obtained data was sufficient to confirm the expected reduction in fatigue stresses, as well as a good connection between the steel deck and the precast UHPFRC slabs. The instrumentation will be continued for several years, along with regular inspections scheduled in one, five and ten years after the intervention, providing important information about the long term behavior of UHPFRC and the structural system.

Unlike the former project, which focused on strain measurements for the global behavior of the compound system, Šajna, Denairé et Brass [47] focused on the evolution of UHPFRC after two years of application over the bridge described in [31]. Several tests were carried out, such as visual inspections, non-destructive tests on site and destructive tests at the laboratory, including pull-off strength, air permeability, capillary absorption and computer tomography based scanning. It is interesting to note that the corrosion rate was measured below the UHPFRC layer by means of embedded corrosion resistance sensors (CRS), allowing both on site and non-destructive data collection.

Even though improved existing structures provide relevant information about the performance of UHPFRC; projects where a monitoring scheme is implemented already in design phase of a new structure can be significantly helpful. In these cases, certain constraints including space restriction and inaccessibility to the failure locations can be avoided with a comprehensive planning, leading to cost reductions and more successful implementations. The UHPFRC arch bridge described in [48] follows this methodology. Distributed fiber optic strain and temperature sensors, in combination with dynamic measurement elements (strain gauges and triaxial accelerometers) were placed on the bridge, effectuating data collection from the construction phase. Another continuous monitoring campaign is implemented in the Gaertnerplatz Bridge (Kassel) [49]. This multispan structure is characterized by the use of a UHPFRC deck and adhesive bond connections with other parts of the bridge. Before it was opened to the public, experimental modal data was measured, via use of an artificial impact hammer, correlating a 
reference FEM model with the results. Thereafter, the monitoring data was used to identify varying parameters in the FEM model that could reflect a structural degradation, finding no issues in three years of study.

\section{ASPECTS TO IMPROVE}

UHPFRC is constantly improving, in terms of mechanical capabilities, costs and modelling. However, several aspects are worth noting related to structural rehabilitation First, its performance under fire loads should be analyzed. Due to its dense microstructure, UHPFRC is more vulnerable to concrete spalling [51], although the problem is reduced when adding polypropylene fibers to the mix. A reasonable compromise between strength resistance and fire safety should be considered, depending on the nature of the project. Secondly, rehabilitation of an existing structure is, in most cases, a more economical and environmentally friendly procedure than demolition and subsequent reconstruction. Monitoring campaigns may provide an invaluable tool for asserting the long-term performance of the latter and its effective response to continually changing environment (ranging operation and environmental action). Furthermore, monitoring could yield salient info regarding the evolution of the cracking phenomenon, the evolution of the bond between different materials as well as the effects of concrete degradation over the synergetic systems, by means of targeted technologies, such as embedded FBG (Fiber Bragg Gratings) on the matrix or image correlation monitoring. Thirdly, the material itself may further be improved, using local and recycled materials for matrix and fibers, respectively. Lastly, updated codes to address UHPFRC as a building material and corresponding provisions for improving existing structures and designing new structures using UHPFRC is required. Despite several efforts achieved in this area, particularly in Switzerland (new SIA code [52]), France (updates in the Association Francaise de Genie Civil, recommendations [53]), Japan [54] and Australia [55], further standardization is expected as the application of UHPFRC becomes more common.

\section{CONCLUSIONS}

This review paper has presented UHPFRC as a competent material for rehabilitation and strengthening of structures. Several observations may be drawn in reference to the driving topics of rehabilitation and monitoring:

\section{Rehabilitation}

- The mechanical characteristics of UHPFRC, along with its low permeability, allow for numerous applications on a wide range of structures, proving its effectiveness under a variety of circumstances. Although commonly employed on bridges, further structural components may benefit from its properties, such as curbs, building slabs or structures in maritime environments.

- UHPFRC can be cast in place or applied as a precast unit, both solutions enhancing the existing lifespan of the structures

- Especially promising is the applicability of UHPFRC when casted at increased slopes, delivering satisfactory results even for $12 \%$ inclination, which permits rehabilitation of surfaces that are not easily accessible by other means. Precast solutions are efficient and economical; however, in reaching full potential, large-scale processing should be implemented.

- A direction of interest pertains to use of prefabricated elements, which however necessitates the development of new connectors, either between slabs or between columns and slabs for buildings. The evolution of these technologies opens a new field, where critical joints of existing structures could exploit UHPFRC, allowing ductile behavior, minimal maintenance and low water infiltration.

\section{Monitoring}

In light of obvious advancements in the field, the behavior of the material should be further 
tested and explored in the coming years. Within this context, SHM and numerical simulation of the material can complement each other in analyzing possible weaknesses of composite structures and in establishing successful and standardized implementations.

- Monitoring of existing structures should be the preliminary step to any intervention, consequently leading to a better examination of the real condition of the construction works. Limited literature exists in this domain, despite the necessity of knowledge of on-site performance for novel materials, which should prevail as a key point on its development.

- Very few long-term monitoring campaigns are available when it is imperative to extract information on long-term performance commonly affected by variations in environmental and operational conditions.

- The new assortment of sensors available on the market has not been fully explored yet. Fiber Brag Gratings (FBGs) or frequency domain reflectometry sensors could be embedded in the cementitious material and provide valuable insight regarding micro-crack propagation [50].

An accurate implementation of the material in numerical models is essential to understand and predict behavior not only during extreme events (e.g. earthquake loads), but additionally for long-term deterioration processes. In materializing these goals, it is important to encourage experimental research as well as field monitoring campaigns for improving the current state-of-knowledge in UHPFRC implementation.

\section{AKNOWLEDGMENTS}

This research is supported by the Swiss National Science Foundation (SNSF) via National research program NRP70 "Energy Turnaround”, under Project \#407040_154060 "Getting more out of Structures through monitoring and simulation".

\section{REFERENCES}

[1] Bastien Masse, M. and Brühwiler, E. 2013. Concrete bridge deck slabs strengthened with UHPFRC. IABSE 2013, Rotterdam.

[2] Duan, L., Noukpo Houankpo, T.O., Dong, P., Wang, C.-S. and Brühwiler, E. 2015. UHPFRC Strengthening method for existing bridges. IABSE ConferenceStructural Engineering: Providing Solutions to Global Challenges September 23-25 2015, Geneva, Switzerland.

[3] Naaman, A.E., and Wille, K. 2012. The Path to Ultra-High Performance, K.Fiber Reinforced Concrete (UHP-FRC): Five Decades of Progress. Proceedings of Hipermat 20123rd International Symposium on UHPC and Nanotechnology for High Performance Construction Materials Kassel, March 7-9, 2012; pp. 315.

[4] Van Zijl, G. P. A. G., Wittmann, F. H., Oh, B.H., Kabele, P., Toledo Filho, R. D., Fairbairn, E. M. R., Slowik, V., Ogawa, A., Hoshiro,H., Mechtcherine, V., Altmann,F. and Lepech, M.D. 2012 Durability of strain-hardening cement-based composites (SHCC) Materials and Structures (2012) 45:1447-1463.

[5] Makita, T. 2014. Fatigue behaviour of UHPFRC and R-UHPFRC - RC composite members. Thèse $N^{o}$ 6068, École Polytechnique Fédérale de Lausanne.

[6] Hebel, K. 2004. Structural behaviour of elements combining ultra-high performance fibre reinforced concretes (UHPFRC) and reinforced concrete. Thèse $N^{\circ}$ 3036, École Polytechnique Fédérale de Lausanne.

[7] Brühwiler, E. and Denarié, E. 2015. Rehabilitation and Strengthening of Concrete Structures Using Ultra-High Performance Fibre Reinforced Concrete. Structural Engineering International 4/2013. pp 450-457.

[8] Hajar,Z., Novarin, M., Servant,C., Généreux, G., Przybyla, D. and Bitar,D. 2013. Innovative solution for strengthening orthotropic decks using UHPFRC: the 
Illzach bridge. RILEM-fib-AFGC Int. Symposium on Ultra-High Performance Fibre-Reinforced Concrete, UHPFRC 2013 - October 1-3, 2013, Marseille, France

[9] Tayeh,B.A., Bakarb, B.H.A., Megat Johari, M. A. and Voo, Y. L. 2013. Utilization of Ultra-High Performance Fibre Concrete (UHPFC) for Rehabilitation - a Review. The 2nd International Conference on Rehabilitation and Maintenance in Civil Engineering, Procedia Engineering 54 (2013) Pp 525 - 538

[10] Tysmans, T., Wozniak, M., Remy, O. and Vantomme, J. 2015. Finite element modelling of the biaxial behaviour of high-performance fibre-reinforced cement composites (HPFRCC) using Concrete Damaged Plasticity. Finite Elements in Analysis and Design 100(2015), pp.47-53.

[11] Xia, J. 2011. Ultra-High Performance Fiber Reinforced Concrete in bridge deck applications. Thesis in the Department of Civil, Environmental, and Construction Engineering at the University of Central Florida,Orlando, Florida

[12] Kunieda, M., Ogura, H., Ueda, N. and Nakamura, H. 2011 Tensile fracture process of Strain Hardening Cementitious Composites by means of three-dimensional meso-scale analysis. Cement \& Concrete Composites 33 (2011) Pp 956-965

[13] Link, M. and Weiland, M. 2012. Structural Health Monitoring of the Gaertnerplatz Bridge over the Fulda River in Kassel Based on Vibration Test Data and Stochastic Model Updating . Proceedings of Hipermat 2012. 3rd International Symposium on UHPC and Nanotechnology for High Performance Construction Materials Kassel,pp. 945-956

[14] Habert, G., Denarié, E. and Rossi, P. Lowering the global warming impact of bridge rehabilitations by using Ultra High Performance Fibre Reinforced Concretes The 2nd International Conference oRehabilitation and Maintenance in Civil Engineering, Procedia Engineering 54 (2013 ) $525-538$
[15] Parant, E., Pierre, R. and Le Maou, F. Durability of a multiscale fibre reinforced cement composite in aggressive environment under service load. Cement and Concrete Research 37 (2007), pp 1106-1114

[16] Naaman A.E, and Reinhardt H.W. Setting the stage: toward performance based classification of FRC composites. Proceedings of 4th RILEM symposium on high performance fiber reinforced cement, composites (HPFRCC4); 2003. Pp. 1-4.

[17]Wille, K., El-Tawil, S. and. Naaman, A.E . 2013. Properties of strain hardening ultra high performance fiber reinforced concrete (UHP-FRC) under direct tensile loading. Cement \& Concrete Composites 48 (2014) pp 53-66.

[18] Kamal, M.M., Safan, M.A., Etman, Z.A., and Salama, R.A. 2013. Behavior and strength of beams cast with ultra high strength concrete containing different types of fibers. HBRC Journal,Volume 10, Issue 1, April 2014, Pp 55-63

[19] Tayeh, B.A., Abu Bakar, B.H., Johari, M.A.M. and Voo, Y.L. 2013. Evaluation of Bond Strength between Normal Concrete Substrate and Ultra High Performance Fiber Concrete as a Repair Material. Procedia Engineering 54 ( 2013 ) Pp 554 563

[20] Yang, S.L., S.G. Millard, S.G.,. Soutsos, M.N., Barnett, S.J. and Le, T.T. 2008. Influence of aggregate and curing regime on the mechanical properties of ultra-high performance fibre reinforced concrete (UHPFRC) Construction and Building Materials. Volume 23, Issue 6, June 2009, Pages 2291-2298

[21] Boshoff, W. P. and Van Zijl, G. 2007.A computational model for strain-hardeningfiber-reinforced cement-based composites. Journal of the South African Institution of Civil Engineers. July 2007.

[22] Oesterlee, C. 2010. Structural Response of Reinforced UHPFRC and RC Composite Members. Thesis $N^{o}$ 4848, École Polytechnique Fédérale De Lausanne.

[23] Sadouki, H., Denarié, E., Žnidarič, A. et al. 2006. Modelling of UHPFRC in composite 
structures. SAMARIS: Sustainable and Advanced Materials for Road Infrastructure. WP 14: HPFRCC for rehabilitation.

[24] Sadouki, H. and E. Brühwiler, E. and Zwicky, D. 2015. Chillon Viaduct deck slab strengthening using reinforced UHPFRC: Numerical simulation of fullscale tests Sadouki H.; Brühwiler E. ; Zwicky D. 4th International Conference on Concrete Repair, Rehabilitation and Retrofitting. Leipzig, Germany.

[25] Ellis, B.D., B.P. DiPaolo, B.P., D.L. McDowell, D.L. and M. Zhou, M. 2014 Experimental investigation and multiscale modeling of ultra-high performance concrete panels subject to blast loading. International Journal of Impact Engineering 69 (2014), pp. 95-103

[26] Trüb, M. 2011. Numerical Modelling of High Performance Fiber Reinforced Cementitious Compoistes. IBK Report N. 333 at Swiss Federal Institute of Technology.

[27] Kunieda, M., Ogura, H. Ueda, N. and Nakamura, H. 2011. Tensile fracture process of Strain Hardening Cementitious Composites by means of three-dimensional meso-scale analysis. Cement \& Concrete Composites 33 (2011), pp 956-965

[28] Lampropoulus, A.P. and Paschalis, S.A. 2016. Strengthening of existing reinforced concrete beams using ultra high performance fibre reinforced concrete. 2016. Concrete Repair, Rehabilitation and Retrofitting IV, 2016, pp 573-579.

[29]Wang, J and Morikawa, H. 2015. Shear strengthening of RC beams using ultrahigh-strength fibre-reinforced concrete panels. Magazine of Concrtete research, 67 (13), pp 718-729.

[30] Bastien-Masse, M. and Brühwiler, E . 2014. Ultra high performance fiber reinforced concrete for strengthening and protecting bridge deck slabs. Bridge Maintenance, Safety, Management And Life Extension, pp.2176-2182.

[31] Denaire, E.,Habert, G. and Sajna, A. 2009 Recommendations for the use of UHPFRC in composite structural members.
Rehabilitation Log Čezsoški bridge. ARCHES deliverable D14.

[32] Full scale application of UHPFRC for the rehabilitation of bridges - from the lab to the field. 2005. SAMARIS Sustainable and Advanced MAterials for Road InfraStructure WP 14: HPFRCC for rehabilitation. Deliverable D22

[33] Bastien-Masse, M. and Brühwiler, E. 2015. Strengthening the Chillon viaducts deck slabs with reinforced UHPFRC. IABSE conference- Structural Engineering: providing solutions to global challenges, Geneva 2015.

[34] Thibaux, T. 2008. Strengthening of Huisne bridge using Ultra-HighPerformance Fibre-Reinforced Concrete. Tailor Made Concrete Structures, 2008.

[35] Perry, V.H. and Seibert, P.J. 2008. The use of UHPFRC (Ductal $\left.{ }^{\circledR}\right)$ for bridges in North America: The technology, applications and challenges facing commercialization. Proceedings of 2nd International Symposium on UHPC Technology, Applications and Challenges Facing Commercialization., Kassel, Germany, pp. 815 - 822.

[36] Sato, Y., Shionaga, R.and Nakamura, Y. 2013. Experimental and analytical investigation on failure behavior of steel plate- HPFRC composite beams. Proceedings of RILEM-fib-AFGC International Symposium on Ultra-High Performance Fibre-Reinforced Concrete, pp 99-106.

[37] Toutlemonde; F. Marchand, P, Gomes, F. and Dieng, L. 2014 Using UHPFRC as a topping layer for orthotropic Bridge decks: prototype validation. Proceedings of RILEM-fib-AFGC International Symposium on Ultra-High Performance Fibre-Reinforced Concrete, Pp. 107-116.

[38] http://rsta.royalsocietypublishing.org/cont ent/365/1851/303

[39] Hajar, Z., Marco Novarin, M., Servant, C., Généreux, G., Przybyla, D. and Bitar, D. 2013. Innovative solution for strengthening orthotropic decks using uhpfrc: the Illzach bridge. Proceedings of RILEM-fib-AFGC International Symposium on Ultra-High 
Performance Fibre-Reinforced Concrete, pp. 117-126.

[40] Dzajic, I., Sajna, A. and.Oslakovic, I.S. 2014. Rehabilitation of steel railway bridges by implementation of UHPFRC deck. $3^{\text {rd }}$ Internationl Conference on Road and Rail Infrastructure, Split, Croatia

Dzajic, I., Sajna, A. and.Oslakovic, I.S 2014.

[41]Guingot, L., Dekhil, D. and Soulier, P. 2013. Strengthening of hydraulic structures with UHPC. Proceedings of RILEM-fibAFGC International Symposium on UltraHigh Performance Fibre-Reinforced Concrete, pp. 137-146

[42] Denarié, E. Jacomo, D., Fady, N. and Corvez, D. 2013 Rejuvenation of maritime signalisation structures with UHPFRC. Proceedings of RILEM-fib-AFGC International Symposium on Ultra-High Performance Fibre-Reinforced Concrete, pp. 157-166

[43] Hizami Abdullah, M.A., Affandi Mohd Zahid, M. Z., Abu Bakar H. B., Nazri, F.M. and Ayob, A. 2015. UHPFRC as repair material for fire-damaged reinforced concrete structure - a review. Applied Mechanics and Materials, Vol. 802, pp 283-289.

[44] Massicotte, B., Dagenais, M.-A. and Lagier, F. Strengthening Bridge Piers using Ultra High Performance Fiber Reinforced Concrete

[45] Tsono, A.G. 2014. An innovative solution for strengthening of old R/C structures and for improving the FRP strengthening method. Structural Monitoring and Maintenance, Vol. 1, No. 3, pp. 323-338.

[46] Denarié, E and Brühwiler, E. 2015. Caston site UHPFRC for improvement of existing structures - achievements over the last 10 years in practice and research. 7 th workshop on High Performance Fiber Reinforced Cement Composites, 1-3, June 2015, Stuttgart, Germany

[47] Šajna, A., Denarié, E. and Bras, V. 2012 Assessment of a UHPFRC based bridge rehabilitation in Slovenia, two years after application. Proceedings of Hipermat 20123rd International Symposium on UHPC and Nanotechnology for High Performance Construction Materials
Kassel, March 7-9, 2012; pp. 937-944.

[48] Friedl, H. Río, O. Freytag, B. and Rodríguez, A. 2010. Advanced bridge monitoring application for analysing actual structural performance of UHPFRC constructions - Wild bridge. $6^{\text {th }}$ CCC Congress MARIANSKE LAZNE 2010.

[49] Link.M. and Weiland, M. 2012. Structural Health Monitoring of the Gaertnerplatz Bridge over the Fulda River in Kassel Based on vibration test data and stochastic model updating. Proceedings of Hipermat 20123rd International Symposium on UHPC and Nanotechnology for High Performance Construction Materials Kassel, March 7-9, 2012; pp. 945-956.

[50] Spiridonakos, M., Chatzi, E.N., Sudret, B., "Polynomial Chaos Expansion Models for Structural health Monitoring under Operational Variability”, Special Issue on Uncertainty Quantification and Propagation in Structural Systems, ASCEASME Journal of Risk and Uncertainty in Engineering Systems - Part A: Civil Engineering, in press.

[51] Way, R. and Wille, K. 2012. Material characterization of an Ultra HighPerformance-Fibre Reinforced Concrete under elevated temperatures. Proceedings of Hipermat 20123rd International Symposium on UHPC and Nanotechnology for High Performance Construction Materials Kassel, March 7-9, 2012; pp.565-572

[52] SIA 2052, 2016. Ultra-HochleistungsFaserbeton (UHFB). Baustoffe, Bemessung und Ausführung, Swiss Society of Architects and Engineers, SIA Zurich.

[53] AFGC / SETRA. 2013. Working Group, "Ultra High Performance Fibre-Reinforced Concrete" - Recommendations, Report, Association Française de Génie Civil, Paris, France.

[54]JSCE, 2006. "Recommendations for Design and Construction of Ultra High Strength Fiber Reinforced Concrete Structucres (Draft). (2004 in Japanese).

[55] AS 3600-2001, “Concrete Structures". Standards Australia, Sydney, Australia. 